\title{
ARTICLE Dorsal and ventral hippocampal adult-born neurons contribute to context fear memory
}

\author{
Kylie A. Huckleberry ${ }^{1}$, Francis Shue ${ }^{1}$, Taylor Copeland ${ }^{1}$, Raymond A. Chitwood ${ }^{1}$, Weiling Yin $^{2}$ and Michael R. Drew ${ }^{1}$
}

The hippocampus contains one of the few neurogenic niches within the adult brain-the subgranular zone of the dentate gyrus. The functional significance of adult-born neurons in this region has been characterized using context fear conditioning, a Pavlovian paradigm in which animals learn to associate a location with danger. Ablation or silencing of adult-born neurons impairs both acquisition and recall of contextual fear conditioning, suggesting that these neurons contribute importantly to hippocampal memory. Lesion studies indicate that CFC depends on neural activity in both the dorsal and ventral hippocampus, subregions with unique extrahippocampal connectivity and behavioral functions. Because most studies of adult neurogenesis have relied on methods that permanently ablate neurogenesis throughout the entire hippocampus, little is known about how the function of adult-born neurons varies along the dorsal-ventral axis. Using a Nestin-CreER ${ }^{\mathrm{T} 2}$ mouse line to target the optogenetic silencer Archaerhodopsin to adult-born neurons, we compared the contribution of dorsal and ventral adult-born neurons to acquisition, recall, and generalization of CFC. Acquisition of CFC was impaired when either dorsal or ventral adult-born neurons were silenced during training. Silencing dorsal or ventral adult-born neurons during test sessions decreased context-evoked freezing but did not impair freezing in a hippocampus-independent tone-shock freezing paradigm. Silencing adult-born neurons modestly reduced generalization of fear. Our data indicate that adult-born neurons in the dorsal and ventral hippocampus contribute to both memory acquisition and recall. The comparatively large behavioral effects of silencing a small number of adult-born neurons suggest that these neurons make a unique and powerful contribution to hippocampal function.

Neuropsychopharmacology (2018) 43:2487-2496; https://doi.org/10.1038/s41386-018-0109-6

\section{INTRODUCTION}

The dentate gyrus (DG) is one of the few regions of the mammalian brain that generates neurons throughout adulthood [1-3]. Neurons born in the adult DG integrate into functional circuits and are believed to contribute to both the cognitive and emotional functions of the hippocampus. Suppression of adult hippocampal neurogenesis alters spatial [4-6] and context memory [7-9], stress resilience [10, 11], anxiety-like behavior [11-13], and the effects of antidepressant treatment $[14,15]$. As a result, adult hippocampal neurogenesis is being investigated as a therapeutic target for the treatment of anxiety and cognitive disorders $[16,17,84]$.

Most studies investigating the role of adult hippocampal neurogenesis in behavior have used techniques that arrest adult neurogenesis permanently throughout the full dorsal-ventral extent of the hippocampus. However, the dorsal and ventral hippocampus are functionally differentiated [18, 19]. The dorsal hippocampus generates more precise spatial representations than the ventral [20]. The ventral but not dorsal hippocampus is reciprocally connected with other limbic structures, including the hypothalamus, the ventral prefrontal cortex, and the amygdala $[21,22]$. Manipulations to the ventral hippocampus alter anxietylike behavior and endocrine regulation but typically do not affect performance on pure spatial tasks. Lesions to the dorsal hippocampus potently impair spatial performance but do not affect anxiety-like behavior and endocrine regulation [23-25]. Thus, the dorsal hippocampus appears specialized for cognitive functions while the ventral hippocampus regulates emotion, motivation, and responses to stress. Because adult neurogenesis occurs throughout the entire dorsal-ventral axis of the DG, the functional contribution of adult-born neurons is likely to vary depending on position along this axis, as has been proposed [26-28].

The contribution of adult-born neurons to hippocampal function has been studied extensively using context fear conditioning (CFC). In CFC, animals acquire fear of a context in which a footshock occurred. The hippocampus contributes to performance in this task in two main ways. It rapidly generates a conjunctive, multimodal memory representation of the context, a process that has been likened to episodic memory [29], and it enables the memory of the context to evoke fear via its interactions with the amygdala [30]. Perturbing either the dorsal or ventral hippocampus during CFC training or CFC expression impairs CFC, suggesting that both regions contribute to acquisition and recall [31-36].

CFC is also impaired by the arrest of adult hippocampal neurogenesis and by ablation or silencing of adult-born neurons $[9,37-39]$. Similar to the effects of hippocampal lesions, the effects of ablating adult neurogenesis are larger in single-trial CFC than in multiple-trial CFC, perhaps because extrahippocampal

\footnotetext{
${ }^{1}$ Center for Learning and Memory and Department of Neuroscience, University of Texas at Austin, Austin, TX, USA and ${ }^{2}$ Division of Pharmacology and Toxicology, College of Pharmacy, University of Texas at Austin, Austin, TX, USA

Correspondence: Michael R. Drew (mdrew@utexas.edu)
}

Received: 29 January 2018 Revised: 6 May 2018 Accepted: 29 May 2018

Published online: 2 June 2018 
A

C
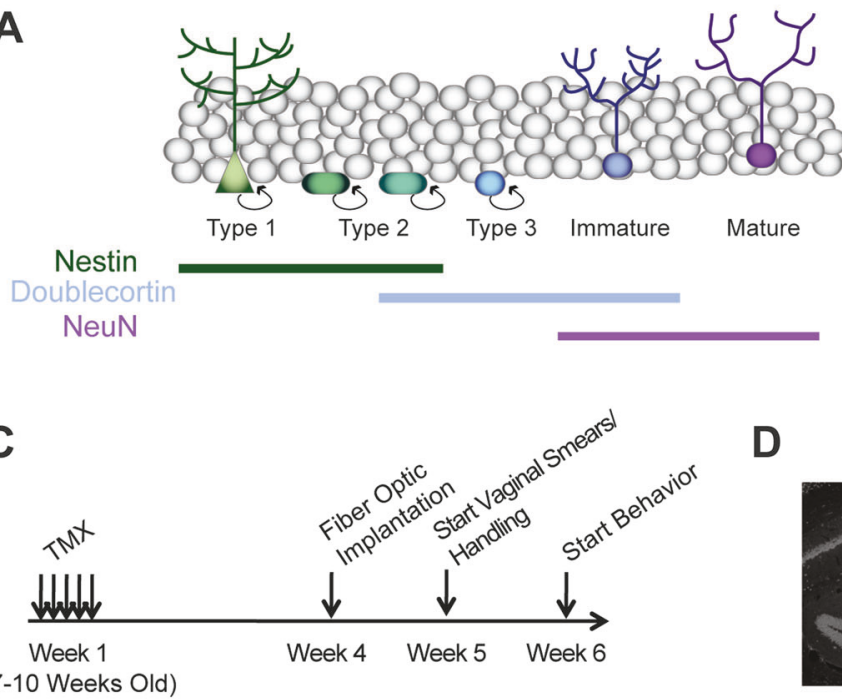

D

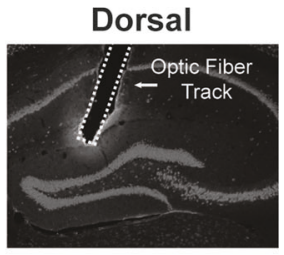

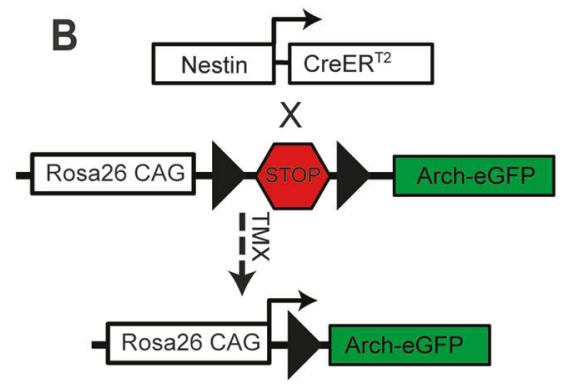

E
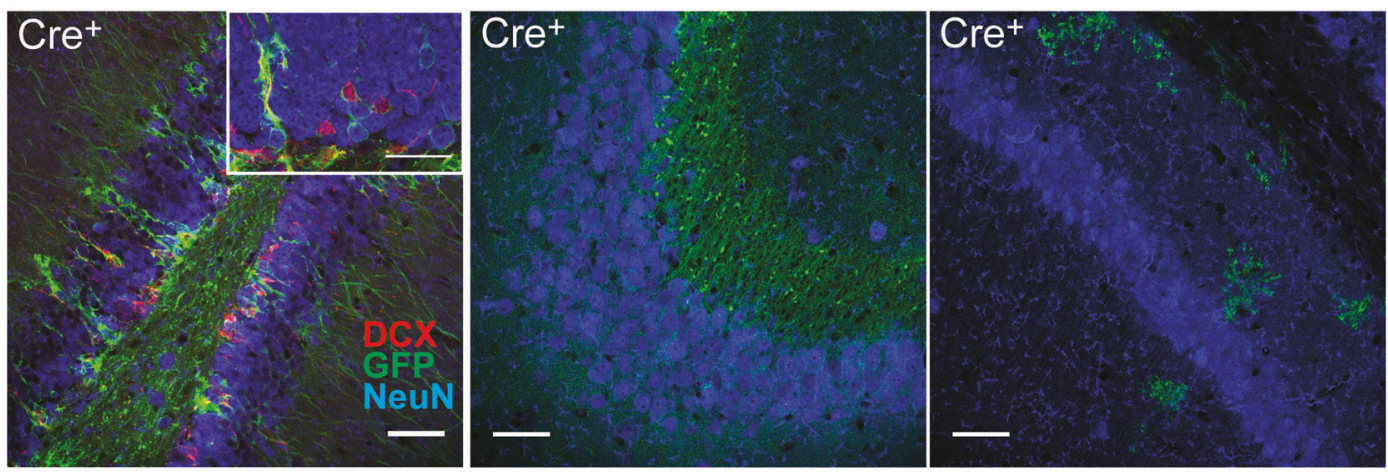

F

G

H
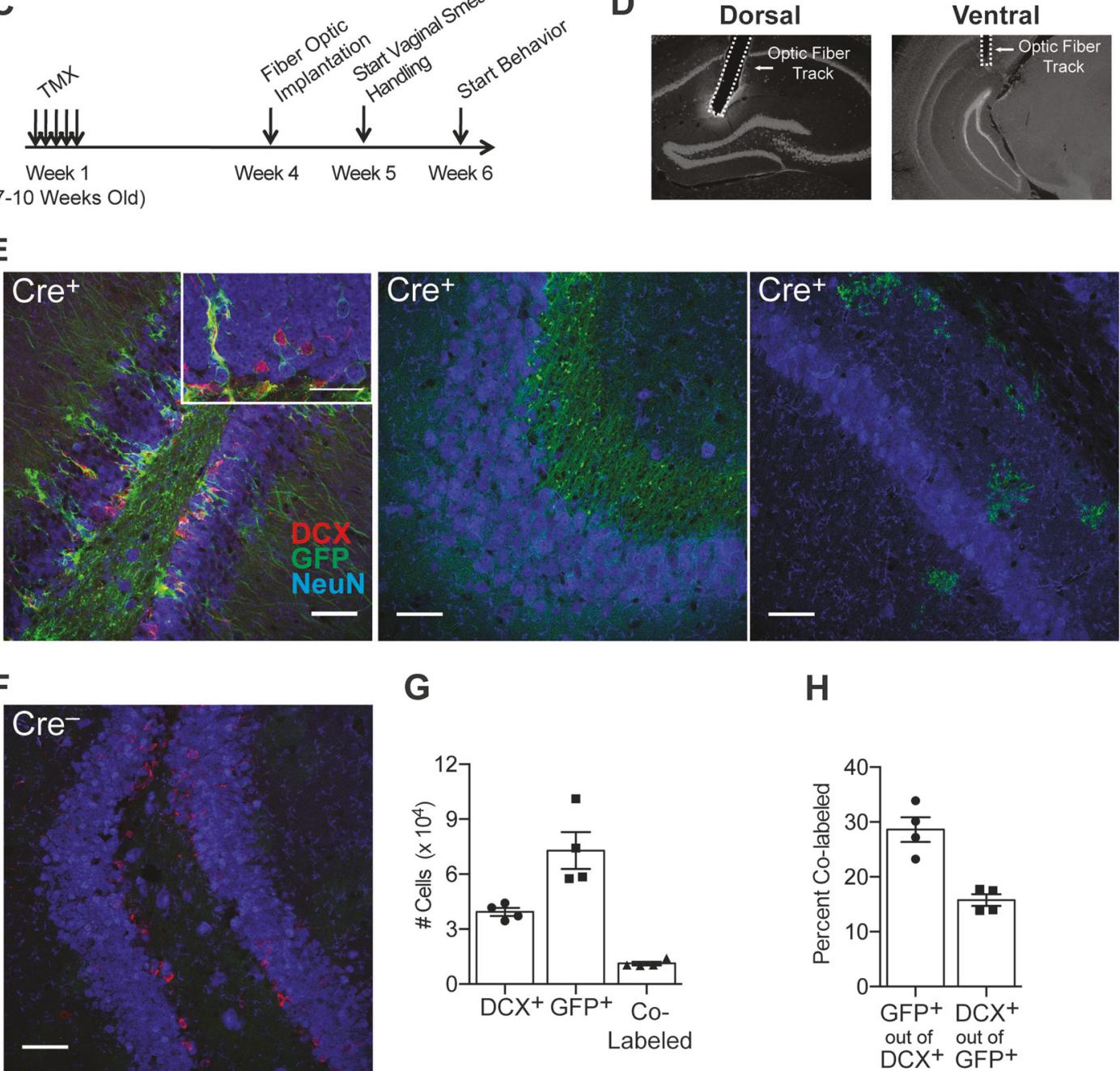

Fig. 1 Arch-GFP is expressed in adult-born neurons in Nestin-CreER ${ }^{T 2}$ mice. a The Cre driver line targeted Nestin-expressing neural stem and progenitor cells, which produce dentate granule cells. Immature adult-born granule cells are identified by doublecortin (DCX) expression. Mature granule cells express NeuN but not DCX. b Nestin-CreER ${ }^{\mathrm{T} 2}$ mice were crossed with the Ai35D Cre-dependent Archaerhodopsin-eGFP mouse line. TMX administration induces Cre expression in the Nestin + neural stem/progenitor cells and their subsequent progeny. c Mice were implanted with optic fibers 4 weeks after the end of induction. Vaginal smears and handling started 5 weeks after induction, and CFC began 6 weeks after TMX induction. $\mathbf{d}$ Representative images of dorsal and ventral optic fiber implants. e, $\mathbf{f}$ Representative images of ArcheGFP (green), DCX (red), and NeuN (blue) expression. In Cre ${ }^{+}$mice, GFP+ neurons were observed in the GCL and subgranular zone of the DG (e, left) but were not present in CA3 (e, middle) or CA1 (e, right). GFP+ cells were not present in Cre ${ }^{-}$mice (f). Scale bars $=50 \mu \mathrm{m}$ or $75 \mu \mathrm{m}$ (inset). $\mathbf{g}$ Stereological estimates of the number of DCX+, GFP+, and co-labeled (DCX+/GFP+) cells in the DG 6 weeks after induction. $\mathbf{h}$ Percentage of DCX + and GFP + neurons co-expressing the other marker. Error bars represent \pm 1 SEM

structures can support CFC when multiple training trials are used [8]. The impairment in CFC arises 4-6 weeks after arrest of adult neurogenesis, suggesting that the impairment is caused by the loss of adult-born neurons that are $4-6$ weeks of age [7, 37], a period when adult-born neurons display enhanced excitability and plasticity $[40,41]$. Because most studies have used anatomically nonspecific techniques or focused exclusively on the dorsal hippocampus, it is not known whether dorsal and ventral adult-born neurons differentially contribute to this form of memory. Furthermore, the contributions of dorsal and ventral adult-born neurons to acquisition vs recall have not been directly compared. 
Here we use optogenetic silencing to investigate the contributions of dorsal and ventral adult-born neurons to acquisition, recall, and generalization of CFC. We use transgenic mice in which the light-sensitive neural silencer archaerhodopsin is inducibly expressed in neural progenitor cells (NPCs) and their progeny. We targeted optic fibers to either the dorsal or the ventral DG and silenced adult-born neurons during the individual stages of CFC. Our data provide the first evidence that both dorsal and ventral adult-born neurons contribute to context fear memory.

\section{METHODS}

Mice

Two strains of mice were crossed for these experiments. The Nestin-CreER ${ }^{\text {T2 }}$ driver line (congenic C57BL/6 background; Jackson Laboratories, stock \#16261) expresses a Cre recombinase-ER ${ }^{T 2}$ fusion protein under the control of the rat nestin promoter [42]. Nestin is an intermediate filament protein expressed in neural progenitor cells in the adult brain. This driver line was crossed with the Ai35D responder line (congenic C57BL/6 background; Jackson Laboratories, stock \#12735), in which expression of a Archaerhodopsin-3-EGFP fusion protein (Arch) is regulated by a loxp-flanked STOP cassette [43]. Pulsing mice with tamoxifen activates $\mathrm{CreER}^{\mathrm{T2}}$ recombinase activity, which initiates permanent Arch expression in the NPCs and their progeny. This line was selected based on evidence that recombination in this line is highly specific to adult neurogenic niches [44].

To generate mice for the experiments, hemizygous Nestin$\mathrm{CreER}^{\mathrm{T2}}$ mice were crossed with homozygous Ai35D mice (Fig. 1a, b). All mice used in experiments were heterozygous at the Ai35D locus (Arch+/-) and either $\mathrm{CreER}^{\mathrm{T} 2+}\left(\mathrm{Cre}^{+}\right)$or $\mathrm{CreER}^{\mathrm{T} 2-}\left(\mathrm{Cre}^{-}\right)$. One hundred and fifty-two female mice $\left(67 \mathrm{Cre}^{+}\right.$and $\left.85 \mathrm{Cre}^{-}\right)$were used in the experiments shown in Figs. 1, 3-5. The behavioral effect shown in Fig. 3 was replicated with an additional 32 male mice (13 $\mathrm{Cre}^{+}$and $19 \mathrm{Cre}^{-}$; Supplementary Figure 2). Three male $\mathrm{Cre}^{+}$Arch mice were used for the electrophysiological recordings in Fig. 2.

Mice were maintained on a 12-h light/dark cycle in a temperature- and humidity-controlled room with food and water provided ad libitum. From birth until the implant surgery, mice were housed in plastic cages with wood chip bedding. After surgery, they were moved to a larger plastic cage with wood chip bedding to permit greater clearance between the cranial implants and cage lid. Experiments were conducted during the light cycle. All procedures were approved by the University of Texas at Austin Institutional Animal Care and Use Committee.

\section{Tamoxifen administration}

Mice (7-10 weeks old) were pulsed with tamoxifen $(180 \mathrm{mg} / \mathrm{kg} /$ day; Sigma-Aldrich, T5648) for 5 days. Tamoxifen (in 10\% ethanol/ $90 \%$ sunflower seed oil) was delivered per os by oral gavage.

Optic fiber construction and implantation

Optic fiber implants were constructed based on published protocols [45, 46], using $1.25 \mathrm{~mm}$ ceramic ferrules (Kientec Systems Inc.) and $200 \mu \mathrm{m}$ core, 0.39 numerical aperture multimode fiber (ThorLabs). Four weeks after induction, mice underwent stereotaxic surgery for optic fiber implantation (Fig. 1c,d). Mice were anesthetized with isoflurane and placed into the stereotaxic frame. Fibers were implanted bilaterally with fiber tips targeted to the dorsal (from Bregma: $A / P-2.0 \mathrm{~mm}$; M/L $\pm 1.3 \mathrm{~mm}$; $\mathrm{D} / \mathrm{V}-1.5 \mathrm{~mm} ; 20^{\circ}$ angle) or the ventral DG (from Bregma: $A / P$ $-3.7 \mathrm{~mm} ; \mathrm{M} / \mathrm{L} \pm 2.6 \mathrm{~mm} ; \mathrm{D} / \mathrm{V}-2.1 \mathrm{~mm}$ ) and secured with dental cement (Fastray Regular Set, Interguide Dental and Medical Supply, 0921376). Coordinates were chosen based on previous studies $[47,48]$.
Electrophysiology

Six weeks after induction, mice were anesthetized with a lethal dose of ketamine/xylazine and transcardially perfused with a cold $\left(\sim 2^{\circ} \mathrm{C}\right)$ modified artificial cerebral-spinal fluid (aCSF) consisting of the following (in mM): 210 sucrose, $1.25 \mathrm{NaH}_{2} \mathrm{PO}_{4}, 25 \mathrm{NaHCO}_{3}, 0.5$ $\mathrm{CaCl}_{2}, 7 \mathrm{MgCl}_{2}, 7$ dextrose, 1.3 ascorbic acid, and 3 sodium pyruvate; bubbled with $95 \% \mathrm{O}_{2}-5 \% \mathrm{CO}_{2}$. Brains were removed and hemisected along the longitudinal fissure. Slices were prepared from the intermediate hippocampus using a vibrating microtome. Slices were then placed in a warmed $\left(\sim 35^{\circ} \mathrm{C}\right)$ holding chamber containing aCSF (in $\mathrm{mM}$ ): $125 \mathrm{NaCl}, 2.5 \mathrm{KCl}, 1.25$ $\mathrm{NaH}_{2} \mathrm{PO}_{4}, 25 \mathrm{NaHCO}_{3}, 2 \mathrm{CaCl}_{2}, 2 \mathrm{MgCl}_{2}, 12.5$ dextrose, 1.3 ascorbic acid, and 3 sodium pyruvate; bubbled with $95 \% \mathrm{O}_{2}-5 \% \mathrm{CO}_{2}$. After incubating in the holding chamber for $20 \mathrm{~min}$, slices were removed and allowed to rest at room temperature for at least $40 \mathrm{~min}$ prior to recording.

Whole-cell current-clamp recordings were performed as previously described [49]. Briefly, hippocampal slices were submerged in a recording chamber continuously perfused with aCSF (32-34 ${ }^{\circ}$ C). GFP+ neurons were identified using a Leica SP5 microscope using $930 \mathrm{~nm}$ 2-photon excitation. After establishing the wholecell configuration, laser photostimulation $(532 \mathrm{~nm}, 2.4-3.6 \mathrm{~mW}$; Laserglow Technologies) was delivered to determine the effectiveness of the Arch construct. Action potentials were generated by somatic current injections (0-100 pA). The number of action potentials as a function of injected current was plotted before and during photostimulation. In addition, the efficacy during prolonged photostimulation was determined using continuous illumination for $3 \mathrm{~min}$.

Optogenetic inhibition

For intracranial light stimulation, patch cables were connected via a rotary joint (Doric Lenses) to a $140 \mathrm{~mW}, 532 \mathrm{~nm}$ laser (Shanghai Dream Lasers Technology (C). Laser output was set to output 7-10 $\mathrm{mW}$ measured at the end of the implant.

For the Light Off condition, an opaque dummy ferrule was placed between the cranial implants and the patch cable, thereby blocking laser light entry into the brain. This configuration was used to equate the ambient light conditions between the Light On and Light Off conditions (due to any green light escaping from the patch cable or ferrule).

Fear conditioning

Apparatus. Fear conditioning was conducted in Med Associates chambers $(30.5 \mathrm{~cm} \times 24.0 \mathrm{~cm} \times 21.0 \mathrm{~cm})$ with three aluminum walls and a clear Plexiglas door and ceiling. Each chamber was housed within a larger, sound-attenuating cabinet equipped with a fan, which generated ambient noise ( $65 \mathrm{~dB})$. During all procedures, chambers were lighted from above with white and infrared lights. An infrared digital camera mounted on the inside of the door of the cabinet recorded mice during all sessions. The experiment room was illuminated with red light during all sessions.

The conditioning chambers could be configured into three contexts as previously described [50]. The training context (Context A) was comprised of a stainless steel rod floor (36 rods evenly spaced $8 \mathrm{~mm}$ from center to center) with a white paper towel covering the waste tray underneath the floor. The chamber was cleaned and scented with $70 \%$ ethanol. The similar alternate context (Context B) had a floor with staggered stainless steels rods (36 rods spaced $8 \mathrm{~mm}$ from center to center with alternating heights) and a brown paper towel in the waste tray underneath the floor and was cleaned and scented with Clorox Fresh Scent antiseptic wipes. The alternate context used for the tone test sessions (Context C) had a white Plexiglas floor covered with wood chip bedding and was cleaned and scented with Clorox Fresh Scent antiseptic wipes. Bedding was replaced between trials. 


\section{Common procedures}

All experiments were run 6 weeks after TMX induction. Mice were handled for 5 days prior to the start of experiments. During each handling session, optic patch cords were connected, and the mice were allowed to explore a cage while tethered to the cables for $\sim 5$ min.

For behavioral experiments, mice were transported to the holding room adjacent to the testing room a minimum of $1 \mathrm{~h}$ prior to experimentation. For Contexts $A$ and $B$, mice were individually transferred to and from the testing room in opaque white containers with clear lids. For Context $C$, mice were individually transferred in gray rectangular boxes with gray lids. Training and testing sessions were video recorded from the side. All handling and behavioral experiments were conducted by women.

\section{Context fear conditioning}

Training occurred on day 1 in Context A. Mice were placed into the conditioning chamber immediately after the optic fiber was connected. A single footshock $(2 \mathrm{~s}, 0.75 \mathrm{~mA})$ was administered $180 \mathrm{~s}$ after the session started. The session ended $30 \mathrm{~s}$ after the footshock.

Mice that received Light On during training were tested in Context A on day 2 and were not tested in Context B. Mice that received Light On during context testing were tested in Contexts $A$ and $B$ in counterbalanced order on days 2 and 3 . Context test sessions were $3 \mathrm{~min}$ without footshock. Fiber optic patch cables were connecting during all sessions.

Tone-shock fear conditioning

Training occurred on day 1 in Context A with Light Off. The tone $(5000 \mathrm{~Hz}, 85 \mathrm{~dB})$ was presented for $20 \mathrm{~s}$ starting at 121, 160, and $220 \mathrm{~s}$ into the 300-s session. Each tone co-terminated with a footshock $(1 \mathrm{~s}, 0.75 \mathrm{~mA})$. Each mouse received two tone test sessions in Context C: one session with Light On (day 2) and one with Light Off (day 3). Tone test sessions were $300 \mathrm{~s}$ in duration. The tone was presented three times during each session at the same time points as during conditioning $(121,160$, and $220 \mathrm{~s}$ after session start). Patch cables were connected during all sessions.

\section{Estrous cycle monitoring}

Mice received daily vaginal smears beginning 1 week prior to fear conditioning and continuing through conditioning $(\sim 10$ days total). The vaginal canal was flushed with $15 \mu \mathrm{l}$ of sterile saline using a $20 \mu \mathrm{l}$ pipette tip. Fluid was then smeared on a Superfrost plus slide (Fisher Scientific). The estrous stage at the time of training and testing was determined based on the pattern of changes in cytology over time [51, 52].

Tissue collection and immunohistochemistry Mice were deeply anesthetized with a mixture of ketamine (150 $\mathrm{mg} / \mathrm{kg}$ ) and xylazine $(15 \mathrm{mg} / \mathrm{kg})$ and transcardially perfused with $25 \mathrm{ml}$ of cold $0.1 \mathrm{M}$ phosphate buffered saline (PBS) followed by $20 \mathrm{ml}$ of $4 \%$ paraformaldehyde in $0.1 \mathrm{M}$ PBS (PFA). Tissue was postfixed for $24 \mathrm{~h}$ in $4 \%$ PFA at $4{ }^{\circ} \mathrm{C}$ then cryoprotected in $30 \%$ sucrose in $0.1 \mathrm{M}$ PBS. Coronal sections $(35 \mu \mathrm{m})$ were cut on a cryostat, and tissue sections were stored in cryoprotectant antifreeze [53].

DCX and NeuN immunohistochemistry were carried out as previously reported [54]. On day 1 , sections were washed three times for $5 \mathrm{~min}$ each in $0.1 \mathrm{M}$ PBS and blocked in 10\% normal donkey serum in $0.1 \mathrm{M}$ PBS with $0.25 \%$ Triton X-100 (PBST) for $1 \mathrm{~h}$ at room temperature. Sections were incubated overnight at room temperature with the primary antibodies in blocking solution (goat anti-DCX 1:1000, Santa Cruz Biotechnology, sc-8066; mouse anti-NeuN 1:1000, Millipore, MAB377). On day 2, tissue sections were washed three times for $5 \mathrm{~min}$ each in $0.1 \mathrm{M}$ PBS followed by a 1-h incubation with secondary antibodies in blocking solution (Biotin-SP-conjugated Affinipure donkey anti-goat 1:500, Jackson Immuno Research, 705-065-003; donkey anti-mouse Cy3 1:500,
Jackson Immuno Research, 715-165-150). Sections were next incubated with a tertiary antibody in blocking solution (Avidin DyLight 649 1:500, Jackson Immuno Research, 016-490-084) at room temperature for $60 \mathrm{~min}$, followed by three 5-min washes in $0.1 \mathrm{M}$ PBS. Sections were mounted onto Superfrost plus slides (Fisher Scientific) and coverslipped with Fluoromount-G (Southern Biotech).

Cell counting

GFP+ and DCX+ cells in the granule cell layer (GCL) and subgranular zone (SGZ) were counted by an experimenter blind to experimental condition. Cells were counted in every 12th section through the DG (7-8 sections total) under fluorescent illumination (Zeiss Axio Imager M2) using the optical fractionator (Stereo Investigator, MBF Bioscience). Counting was carried out using a $40 \times$ objective (Plan-Neofluar). The counting frame $(70 \mu \mathrm{m} x$ $70 \mu \mathrm{m})$ and sampling grids ( 15 sites/section) were optimized to include at least 200 cells of each cell type of interest. Each GFP+ or $\mathrm{DCX}+$ cell was examined for co-localization with the other antigen.

\section{Data analysis}

Freezing and distance traveled during the shock were quantified using AnyMaze software (Stoelting). Some videos were also scored by an experimenter blind to experimental condition using Stopwatch+ (Georgia State University, Center for Behavioral Neuroscience). Scoring by AnyMaze and the blind experimenter were highly correlated $\left(r^{2}=0.975, p<0.001\right)$.

Statistical analyses were performed using Prism 6 (GraphPad software) and JMP PRO 12 (SAS Institute Inc.). Significant interactions were probed using pairwise Sidak's multiple comparison test (post hoc comparisons).

\section{RESULTS}

\section{Nestin-CreER ${ }^{\top 2}$ Arch-EGFP mice}

To assess the specificity and efficiency of Cre-mediated recombination, the brains of $\mathrm{Cre}^{+} / \mathrm{Arch}^{+/-}$mice were examined 6 weeks after TMX induction $(n=4)$. GFP + neurons were observed only in the SGZ and GCL of the DG (Fig. 1e, left panel), the subventricular zone, the rostral migratory stream (the olfactory bulb was not examined), and the periventricular hypothalamus. Within the hippocampus, we did not observe GFP+ neurons in the DG hilus, CA3 (Fig. 1e, center panel), or CA1, although a small number of GFP+ oligodendrocytes were observed in CA1 (Fig. 1e, right panel). GFP + cells were absent in $\mathrm{Cre}^{-}$mice (Fig. 1f). We quantified GFP+ and DCX + cells in the GCL and SGZ (Fig. 1g). Relative to other Nestin-CreER ${ }^{\text {T2 }}$ lines, the current line was reported to exhibit the highest specificity for neural progenitors but lower recombination efficiency [44]. In the present experiments, the recombination efficiency is estimated at $30 \%$ based on the percentage of $\mathrm{DCX}+$ immature granule cells co-expressing GFP (Fig. 1h). Less than $20 \%$ of GFP+ granule cells expressed DCX (Fig. 1h), suggesting that the majority of GFP + neurons had matured out of the DCX + stage, as would be expected based on evidence that DCX + expression ceases between 2 and 4 weeks of cell age in mice [26].

To compare the extent of labeling in dorsal and ventral DG, we estimated cell densities in the first four sections (dorsal DG) and the final two sections (ventral DG) of the six-section series (Supplementary Figure 1). DCX+ and GFP+ neurons were abundant in both the dorsal and ventral DG. Consistent with reports that the rate of neurogenesis is higher in the dorsal than in the ventral DG [27], the density of GFP+ cells was higher in the dorsal than in the ventral sections $\left(t_{6}=2.643, p=0.038\right)$. The density of immature DCX + neurons did not differ between the dorsal and ventral DG $\left(t_{6}=1.649, p=0.150\right)$, perhaps reflecting that ventral adult-born neurons mature more slowly than dorsal neurons [55] and thereby may retain DCX expression for a longer 


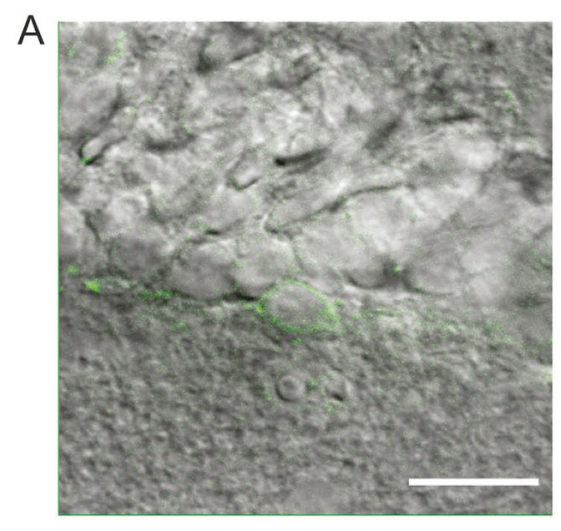

C

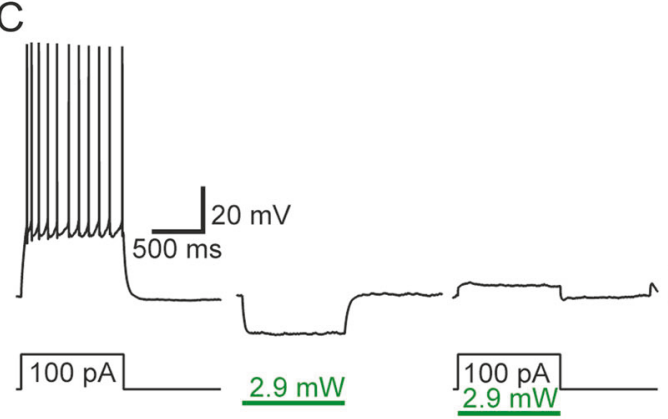

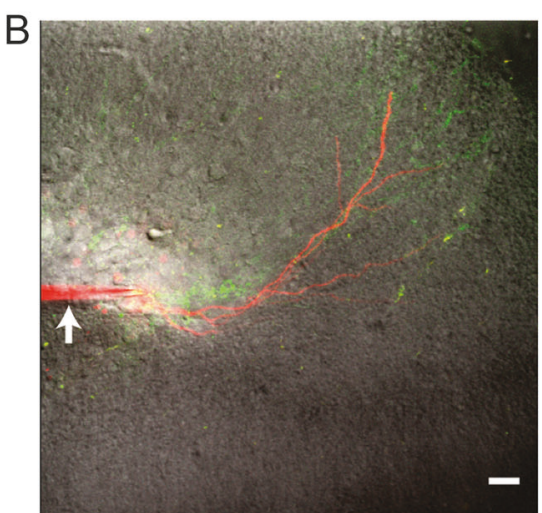

D

E

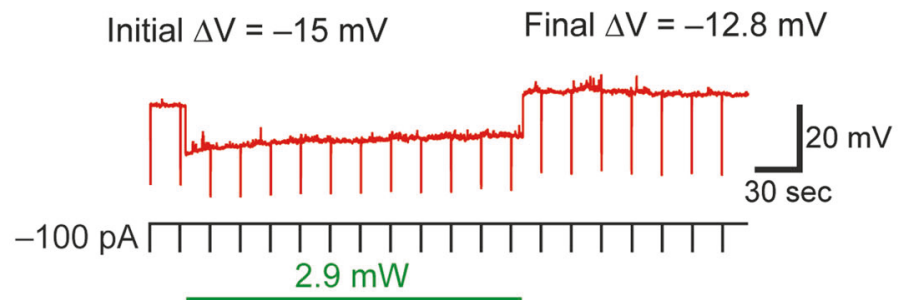

Fig. 2 Whole-cell patch recordings demonstrate Arch-mediated silencing of adult-born neurons. a, b Representative images of a patched GFP + granule cell. Arrowhead denotes patch pipet. Scale bars $=20 \mu \mathrm{m}$. c Photostimulation ( $2.9 \mathrm{~mW}$, green bar) induced a sustained hyperpolarizing current. d Arch-mediated silencing was sufficient to block spiking for a range of depolarizing current injections ( $n=3$ ). e To determine the effectiveness during prolonged photostimulation similar to that used during behavior, membrane potential hyperpolarization was quantified using continuous illumination for $3 \mathrm{~min}$. No rebound spiking was observed following any duration of photostimulation

period. The density of DCX/GFP double-positive cells was also higher in the dorsal than in the ventral DG $\left(t_{6}=4.134, p=0.006\right)$.

In vitro confirmation of Arch-mediated silencing

To confirm that photostimulation with green light silenced GFP+ adult-born neurons, whole-cell recordings were performed on ex vivo slices from three $\mathrm{Cre}^{+} / \mathrm{Arch}^{+-}$mice (Fig. 2a, b). Photostimulation (2.4-3.6 $\mathrm{mW}$ ) induced a sustained hyperpolarizing current. Arch-mediated silencing was sufficient to block spiking for a range of depolarizing current injections (Fig. 2c, d). To determine the effectiveness during prolonged photostimulation similar to that used during behavior, membrane potential hyperpolarization was quantified using continuous illumination for $3 \mathrm{~min}$. (Fig. 2e). The initial hyperpolarization magnitude was compared to the ending magnitude and found to be $89 \%$ (SEM \pm 2.2) of the initial value. No rebound excitation was observed. These data suggest that photostimulation of Arch-GFP+ neurons is sufficient to reversibly inhibit the generation of action potentials in GFP+ adult-born neurons.

Dorsal and ventral adult-born neurons contribute to CFC acquisition

We first assessed the contribution of dorsal and ventral adult-born neurons to acquisition of CFC. Six weeks after induction, $19 \mathrm{Cre}^{+}$ mice (Dorsal: $n=9$; Ventral $n=10$ ) and 25 of their $\mathrm{Cre}^{-}$littermates (Dorsal: $n=11$; Ventral: $n=14$ ) received CFC training with the Light On (Fig. 3a). The next day, mice received a context test session with the Light Off. During the training session, baseline (preshock) freezing was low in all the groups (Fig. 3b). Distance traveled during the footshock (Fig. 3c), a measure of shock reactivity, was comparable between the groups (Genotype: $F_{1,40}=$ 1.346, $p=0.253$; Implant Location: $F<1$; interaction: $F<1$ ).

In the context test session with the Light Off, data were analyzed using a two-way ANOVA with Genotype ( $\mathrm{Cre}^{-}$vs $\mathrm{Cre}^{+}$) and Implant Location (Dorsal vs Ventral) as the factors. There was a significant effect of Genotype on freezing (Fig. $3 d ; F_{1,40}=8.873, p$ $=0.005)$. There was no significant effect of Implant Location $\left(F_{1,40}\right.$ $=1.512, p=0.226)$ or interaction $(F<1)$. These data indicate that both dorsal and ventral adult-born neurons are necessary for acquisition of context fear.

To test for effects of genotype or light unrelated to neuronal silencing, additional $\mathrm{Cre}^{+}$mice (Dorsal: $n=4$; Ventral: $n=8$ ) and Cre ${ }^{-}$littermates (Dorsal: $n=4$; Ventral: $n=10$ ) were fear conditioned and tested with the Light Off during all sessions (Fig. 3e, f). We used a one-way ANOVA to compare these control groups

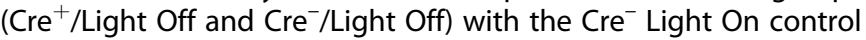
group reported above and in Fig. 3d. In the context test session, there was no effect of Group on freezing $(F<1)$. The absence of an 
A

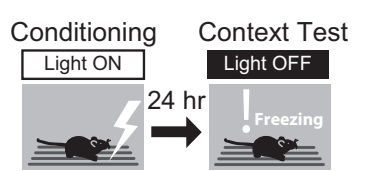

B
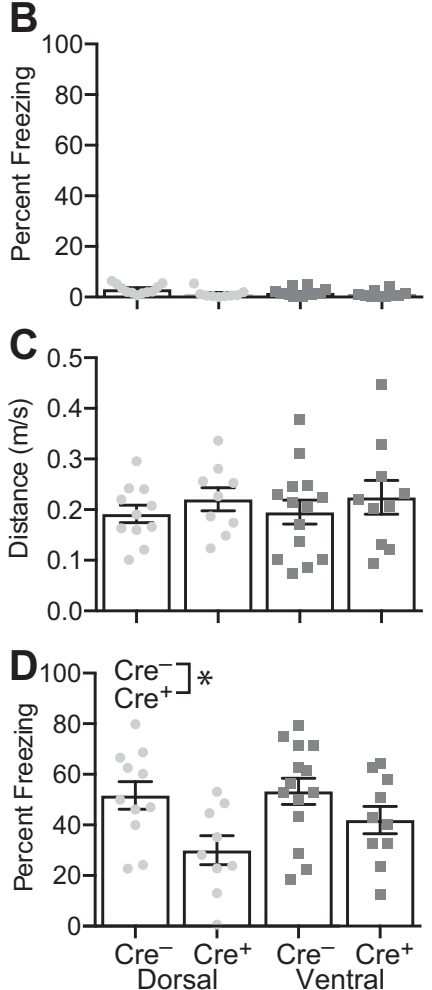

E

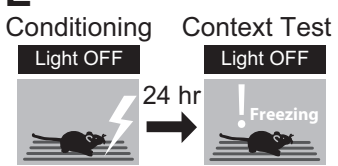

F

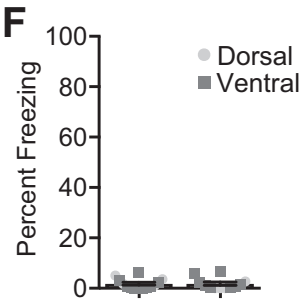

G
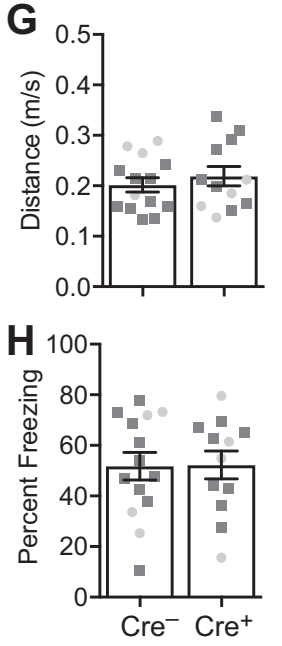

Fig. 3 Silencing dorsal or ventral adult-born neurons impairs CFC acquisition. a Cre ${ }^{+}$mice (Dorsal: $n=9$; Ventral: $n=10$ ) and their $\mathrm{Cre}^{-}$ littermates (Dorsal: $n=11$; Ventral: $n=14$ ) received CFC training with the Light On. The next day, mice were tested in the shock context with the Light Off. b, c In the training session, preshock freezing was uniformly low (b), and distance traveled during the shock was comparable between the groups (c). $\mathbf{d}$ In the test session, silencing dorsal or ventral adult-born neurons significantly decreased freezing $\left(F_{1,40}=8.873, p=0.005\right)$. e To rule out nonspecific effects of genotype or light, additional $\mathrm{Cre}^{+}$(Dorsal: $n=4$; Ventral: $n=8$ ) and Cre ${ }^{-}$littermates (Dorsal: $n=4$; Ventral: $n=10$ ) were trained and tested with the Light Off. f Baseline (preshock) freezing was uniformly low. $g$ Distance traveled during the shock was comparable between the groups. $\mathbf{h}$ There was no effect of group on freezing in the context test session $\left(F_{2,22}=0.303, p=\right.$ $0.741)$. Error bars represent \pm 1 SEM

effect indicates that light stimulation has no effect in $\mathrm{Cre}^{-}$mice and that the Cre genotype has no effect on conditioning in the absence of light stimulation. The results thereby confirm that the impairment in fear conditioning caused by light stimulation in the $\mathrm{Cre}^{+}$mice (Fig. 3d) represents the effect of silencing adult-born neurons.

To test whether the results generalize to males, male Ventral $\mathrm{Cre}^{+}(n=7)$ and Ventral Cre ${ }^{-}$mice $(n=9)$ received CFC training with the Light On followed by a context test with the Light Off. Similar to what we observed in females, during the context test, freezing was significantly lower in $\mathrm{Cre}^{+}$than in $\mathrm{Cre}^{-}$males (Supplementary Figure $2 \mathrm{~A} ; t_{14}=2.258, p=0.040$ ). To rule out nonspecific effects of genotype and light, additional male Ventral $\mathrm{Cre}^{+}(n=6)$ and Ventral Cre ${ }^{-}$mice $(n=10)$ were trained and tested with the Light Off during both sessions. One-way

ANOVA was used to compare these male control groups ( $\mathrm{Cre}^{+} /$Light Off and $\mathrm{Cre}^{-} /$Light Off) with the $\mathrm{Cre}^{-}$Light On control group shown in Supplementary Figure 2A. There was no effect of Group on freezing (Supplementary Figure 2B; $F<1$ ), ruling out nonspecific effects of genotype or light exposure. These results demonstrate that the activity of ventral hippocampal adult-born neurons is required for CFC acquisition in both female and male mice.

Both dorsal and ventral adult-born neurons contribute to recall of CFC

Next, we assessed the contribution of dorsal and ventral adultborn neurons to the expression and generalization of contextevoked fear. Thirty-two Cre ${ }^{+}$(Dorsal: $n=18$; Ventral: $n=14$ ) and 42 of their $\mathrm{Cre}^{-}$littermates (Dorsal: $n=23$; Ventral: $n=19$ ) were fear conditioned in Context A with the Light Off. On the two days following conditioning, mice were tested with the Light On in Context A and a similar context, B, in counterbalanced order (Fig. 4a).

During the conditioning session with the Light Off, preshock freezing was low in all the groups (Fig. 4b). Distance traveled during shock (Fig. 4c) was comparable between the groups (Genotype: $F<1$; Implant Location: $F<1$; Interaction: $F_{1,70}=1.728$, $p=0.193)$. The data from the test sessions in Contexts $A$ and $B$ with the Light On (Fig. 4d) were analyzed using a three-way ANOVA with Context (Original or Alternate) as a within-subject factor and Genotype $\left(\mathrm{Cre}^{-}\right.$vs $\left.\mathrm{Cre}^{+}\right)$and Implant Location (Dorsal vs Ventral) as between-subject factors. The full ANOVA results are reported in Supplementary Table 1. Silencing dorsal or ventral adult-born neurons significantly reduced fear expression $\left(F_{1,70}=\right.$ $25.139, p<0.001)$. All groups froze more in the original than in the similar context $\left(F_{1,70}=54.480, p<0.001\right)$. There was no significant effect of implant location $\left(F_{1,70}=0.004, p=0.952\right)$ or significant interactions $\left(F^{\prime} S<1\right)$. The results indicate that both dorsal and ventral adult-born neurons are required for expression of context fear.

To further characterize generalization of fear, we calculated a discrimination ratio expressing freezing in Context $A$ as a proportion of total freezing $[A /(A+B)$; Fig. 4e]. All groups discriminated significantly better than chance (one-sample $t$-tests, $\left.p^{\prime} s \leq 0.008\right)$. Silencing the dorsal and ventral adult-born neurons significantly enhanced discrimination $\left(F_{1,70}=7.289, p=0.009\right)$. There was no significant effect of implant location $\left(F_{1,70}=1.307, p\right.$ $=0.257)$ or interaction $(F<1)$. Further analysis of the data (Supplementary Tables 2 and 3; Supplementary Figure 3) revealed that the enhanced discrimination in $\mathrm{Cre}^{+}$mice was dependent on the test order: $\mathrm{Cre}^{+}$mice displayed enhanced discrimination only when tested in the Original $\rightarrow$ Similar order (Original $\rightarrow$ Similar: Genotype effect, $p=0.0008$; Similar $\rightarrow$ Original: Genotype effect, $p=0.739)$. Nevertheless, these data indicate that silencing adultborn neurons significantly reduces the expression of context fear but may improve discrimination between similar conditioned and non-conditioned contexts.

Stage of estrous cycle at the time of conditioning had no effect on freezing levels

Because estrogen levels can affect spatial learning [56] and CFC [57], we evaluated whether differences in estrous stage could account for the group differences observed in our experiments. Estrous cycle was tracked over the course of ten days in 38 mice (Supplementary Figure 4A; Dorsal $\mathrm{Cre}^{+}: n=13$; Dorsal Cre ${ }^{-}$: $n=19$ ). As shown in Supplementary Figure $4 B, C$, there was no significant effect of estrous cycle at the time of training or testing on freezing during the context test (Supplementary Figure 4B, C; training: $F_{2,29}=1.737, p=0.194$; testing: $\left.F_{2,29}=2.535, p=0.097\right)$. Furthermore, the distribution of estrous stages during training and testing did not differ between $\mathrm{Cre}^{+}$and $\mathrm{Cre}^{-}$groups (training: $x_{2}^{2}=0.475, p=0.789$; testing: $X_{2}^{2}=3.345, p=0.188$ ). 

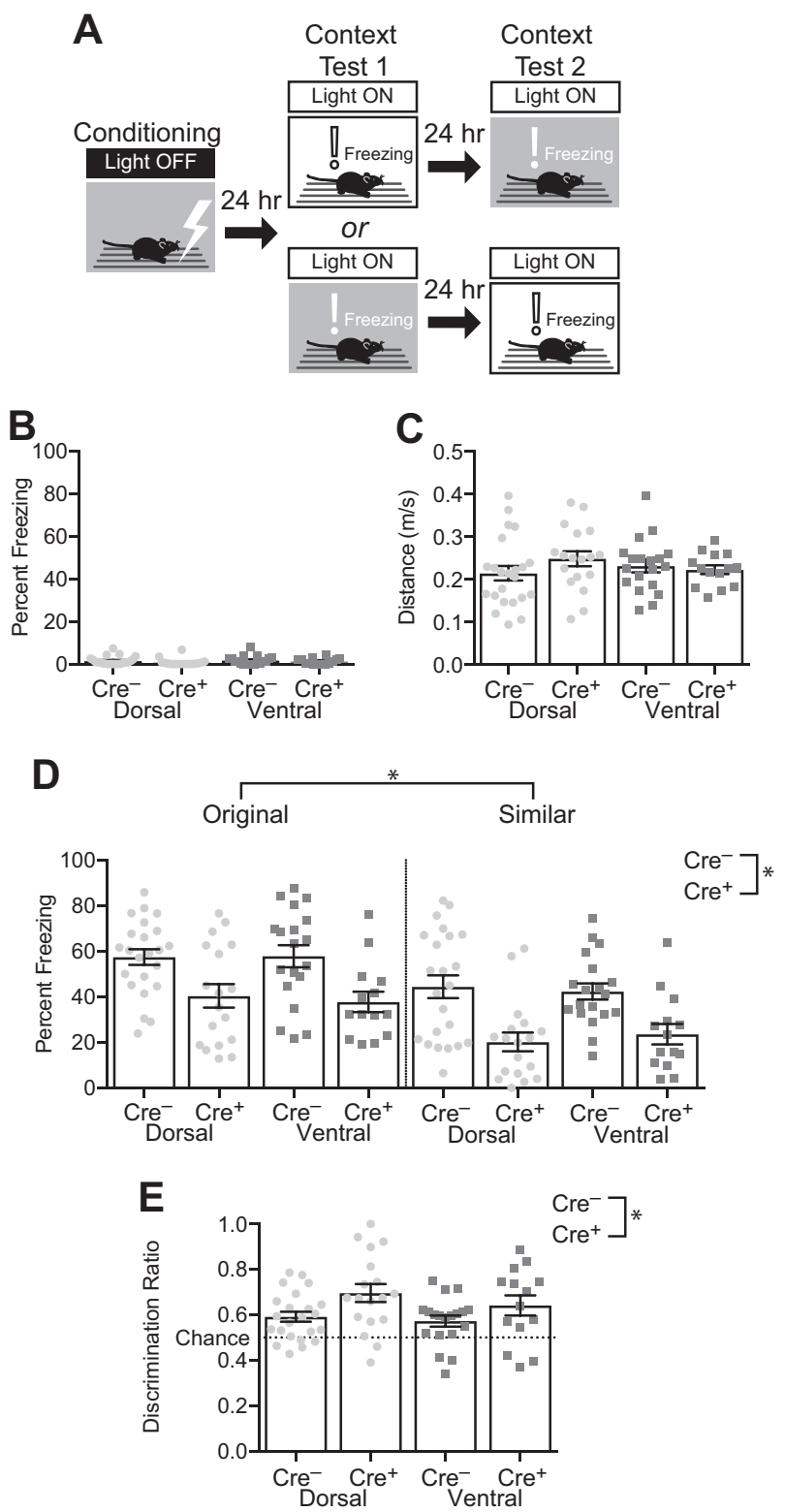

Fig. 4 Silencing dorsal or ventral adult-born neurons impairs expression of context fear. a Cre ${ }^{+}$mice (Dorsal: $n=18$; Ventral: $n$ $=14$ ) and Cre ${ }^{-}$littermates (Dorsal: $n=23$; Ventral: $n=19$ ) were fear conditioned with the Light Off and then tested in the training context and a similar alternate context with the Light On. b Baseline (preshock) freezing was uniformly low. c Distance traveled during the shock was comparable between the groups. d Silencing Dorsal or Ventral adult-born neurons reduced freezing in both the original and similar contexts $\left(F_{1,70}=25.139, p<0.001\right)$. All groups froze more in the original than the similar context $\left(F_{1,70}=54.480, p<0.001\right)$. e All groups discriminated significantly better than chance ( $p$ 's $\leq 0.008$ ). Silencing the dorsal and ventral adult-born neurons significantly enhanced discrimination $\left(F_{t_{1}, 70}=7.289, p=0.009\right)$. Error bars represent \pm 1 SEM

Silencing ventral adult-born neurons has no effect on the expression hippocampus-independent fear

The effect of silencing adult-born neurons on CFC expression could reflect impaired recall of context fear or it could reflect a more general suppression of fear expression. To differentiate between these interpretations, we assessed the effects of silencing adult-born neurons in hippocampus-independent tone-shock fear conditioning [58]. Ventral $\mathrm{Cre}^{+}$mice $(n=4)$ and Cre $^{-}$mice $(n=4)$
A
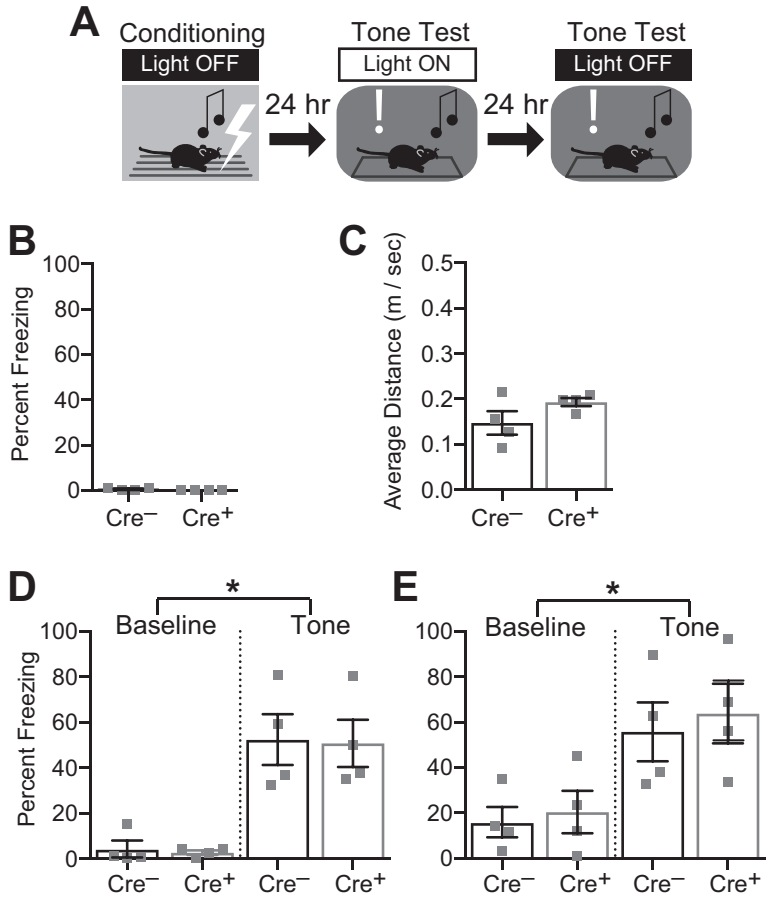

Fig. 5 Silencing adult-born neurons does not impair expression of hippocampus-independent fear. a To determine whether silencing adult-born neurons impairs hippocampus-independent conditioned fear, mice with ventral implants $\left(\mathrm{Cre}^{+}: n=4 ; \mathrm{Cre}^{-}: n=4\right)$ received tone-shock pairings with the Light Off. Tone-elicited fear was tested in a different context twice, first with the Light On and then with the Light Off. b Baseline (preshock) freezing was uniformly low. c Distance traveled during the shock was comparable between the groups. d, e There was no effect of Genotype during the Light On test (d) or the Light Off test (e). During both test sessions, tone freezing exceeded baseline (pre-tone) freezing $\left(F_{1,6}=70.589\right.$, $p=0.002)$. Error bars represent \pm 1 SEM

received three tone-shock pairings in the conditioning chamber with the Light Off. On the two following days, mice received tone test sessions in a different context, $C$. The first test session was conducted with the Light On for the entire session; the second test was conducted with the Light Off (Fig. 5a).

During training, levels of preshock freezing were uniformly low (Fig. 5b), and average distance during the shock was comparable between the groups (Fig. $5 c ; t_{6}=1.669, p=0.146$ ). The tone test data (Fig. 5d, e) were analyzed using a three-way ANOVA with Light (Off vs On) and Period of Test (Baseline or Tone) as the within-subject factors and Genotype (Ventral $\mathrm{Cre}^{-}$or Ventral $\mathrm{Cre}^{+}$) as a between-subject factor (Supplementary Table 4). There was a significant effect of Period $\left(F_{1,6}=70.589, p=0.002\right)$, confirming that tone freezing exceeded pre-tone freezing. There was no effect of Light $\left(F_{1,6}=4.210, p=0.086\right)$ or Genotype $(F<1)$ or any interaction $\left(p^{\prime} s \geq 0.294\right)$, indicating that silencing the adult-born neurons failed to impair expression of hippocampus-independent fear.

\section{DISCUSSION}

We used optogenetics to selectively silence adult-born granule cells in the dorsal or ventral hippocampus during the individual phases of CFC. There were four main results. First, silencing dorsal or ventral adult-born neurons during training impaired acquisition of context fear. Second, silencing dorsal or ventral adult-born neurons during recall was sufficient to impair expression of CFC. Third, context-evoked freezing was reduced during silencing in both the original (training) context and a similar alternate context, 
with silencing adult-born neurons modestly decreasing generalization of context-evoked fear. Finally, silencing did not reduce freezing to a tone $\mathrm{CS}$, a hippocampus-independent form of conditioned fear. These data indicate that dorsal and ventral hippocampal adult-born neurons contribute to both the acquisition and recall of hippocampus-dependent memory. To our knowledge, this is the first study to demonstrate that both dorsal and ventral adult-born neurons contribute to CFC.

The most interesting result may be that silencing adult-born neurons impaired expression of CFC, consistent with an earlier report by Gu et al. [37]. This stands in contrast with the effects of larger-scale DG manipulations, which often fail to affect expression of hippocampus-dependent memory. Using CFC procedures very similar to the one used here, we and others found that silencing a large, random population of granule cells (young and old cells) fails to impair expression of CFC $[45,48]$. Similarly, lesioning the DG impairs acquisition but not recall of hippocampus-dependent spatial memory [59]. Silencing a sparse, random population of granule cells similar in size to the population silenced in this study also fails to impair expression of CFC [60]. Thus, it appears that silencing a relatively small population of adult-born granule cells has a larger effect on memory recall than does silencing a similar or larger population of young and old granule cells. We can envision two explanations for this apparent paradox.

One possibility is that young neurons are overrepresented in the DG memory representation. Expression of CFC is believed to be mediated by reactivation of the sparse ensemble of granule cells that were active during CFC acquisition, the so-called "engram cells" [61-63]. Compared to fully mature neurons, young adult-born neurons are less inhibited, more excitable, and more plastic $[40,41,64]$. These factors could cause young adult-born neurons to be overrepresented in the engram cell population. If so, the effect of silencing young adult-born neurons should be similar to the effect of silencing the engram cells. Indeed, silencing engram cells [61] or adult-born neurons (current study and [37]) cause similar impairments in expression of CFC. However, studies using immediate-early gene expression to characterize memory networks provide only mixed support for the hypothesis that young adult-born cells are more readily recruited into memory representations than are fully mature cells $[26,65-68]$.

A second reason why silencing adult-born neurons has a comparatively large effect on retrieval could be because these cells strongly modulate activity in the DG. Young adult-born neurons might enforce sparse coding in the DG by increasing activity of inhibitory interneurons [69]. Consistent with this hypothesis, ablating adult neurogenesis increases excitability of the DG, whereas enhancing incorporation of adult-born neurons can reduce excitability $[69,91]$. Furthermore, direct optogenetic stimulation of young adult-born neurons activates IEG expression in DG and CA3 interneurons [70, 71]. The extent to which these properties are unique to adult-born neurons is unknown because these studies did not directly compare the recordings and manipulations with those targeted to developmentally generated neurons. Furthermore, another recent study reported that young (4-week-old) adult-born neurons are relatively ineffective at activating inhibitory networks [72]. Nevertheless, if young neurons have a strong modulatory role, then the inhibition of these cells would likely perturb activity in the DG and interfere with retrieval processes. Silencing a larger, random population of granule cells might have a comparatively weak effect on retrieval because the broader silencing would prevent aberrant activity in the DG from interfering with retrieval processes in downstream regions such as CA3, as discussed by Bernier et al. [45].

Our finding that silencing the adult-born neurons during retrieval reduced generalization of fear to a similar context is difficult to reconcile with the theory that adult neurogenesis contributes to DG pattern separation. Pattern separation-the mapping of hippocampal inputs onto more distinct neural ensemble representations-is believed to reduce memory interference and generalization of spatial and contextual memories [73, 74]. Arrest of adult neurogenesis impairs performance in behavioral pattern separation tasks, which assess the ability of rodents to discriminate among similar places or contexts [75-78]. What many of the studies demonstrating a role for adult neurogenesis in behavioral discrimination/generalization have in common is that adult neurogenesis was suppressed during the entirety of training. In comparison, our finding that spontaneous behavioral discrimination was improved when the activity of adult-born neurons was suppressed during the test sessions suggests that the effects of adult-born neuron activity during memory acquisition may differ from the effects adult-born neuron activity during memory retrieval. Consistent with this idea, Danielson et al. [47] found that silencing adult-born neurons during context discrimination training impaired the discrimination whereas silencing during test sessions after training did not impair the discrimination.

We found that silencing adult-born neurons reduced context generalization when mice received a test session in the original context followed by a test session in the similar context, but not when the tests occurred in the reverse order. Huckleberry et al. [50] hypothesized that order effects on context generalization could reflect context extinction caused by the test sessions [79] or reconsolidation effects $[80,81]$. It is also possible that the activity of adult-born neurons increases memory generalization. If young, adult-born neurons are preferentially incorporated into hippocampal engrams, this might link together memories of events occurring close together in time [82]. The factors that could affect the incorporation of adult-born neurons (e.g., hyperexcitability and -plasticity) last for a few weeks, potentially causing the same young neurons to be incorporated into the engrams for multiple events that occur in close temporal proximity $[82,83]$. If so, silencing the overlapping parts of these engrams might enhance discrimination but impair retrieval overall.

Our data suggest that dorsal and ventral adult-born neurons both contribute to CFC. Acquisition and expression of CFC were impaired by both dorsal and ventral silencing. Although we were unable to detect differential effects of dorsal vs ventral silencing, we nevertheless speculate that adult-born neurons in dorsal and ventral hippocampus have distinct functions [84]. This hypothesis is based on anatomical and behavioral evidence that the dorsal and ventral hippocampus subserve different functions. The dorsal hippocampus generates more informative spatial representations than does the ventral hippocampus, and lesions to the dorsal hippocampus impair spatial memory whereas ventral lesions do not $[25,85]$. Hippocampal projections to the amygdala arise from the ventral hippocampus [30,86-88], and lesions to the ventral hippocampus alter anxiety-like behavior, stress responses, and defensive behaviors $[23,85,89,90]$. We hypothesize that dorsal adult-born neurons contribute to the acquisition and recall of context representations, whereas ventral adult-born neurons modulate the ability of these representations to activate fear via hippocampal projections to the amygdala. Consistent with this model, arrest of ventral but not dorsal neurogenesis attenuates the anxiolytic effects of antidepressant drugs, whereas both ventral and dorsal neurogenesis affect performance in a context fear discrimination task [28].

To our knowledge, ours is the first study to demonstrate that silencing even a modest proportion of dorsal or ventral adultborn neurons is sufficient to impair acquisition and expression of CFC. In light of previous studies showing that large-scale manipulations of the DG fail to impair memory retrieval, the comparatively large effects of silencing adult-born neurons suggest that these neurons make a unique and powerful contribution to memory [91]. 


\section{ACKNOWLEDGEMENTS}

We thank Stephanie Shea and Devika Palaniswamy for assistance with animal husbandry, genotyping, optic fiber fabrication, and behavior testing. This work was supported by National Institutes of Health Grants R01MH102595 and R21EY026446 and UT Brain Grant UTS-NNRI 365289 to M.R.D.

\section{ADDITIONAL INFORMATION}

Supplementary Information accompanies this paper at (https://doi.org/10.1038/ s41386-018-0109-6).

Competing interests: The authors declare no competing interests.

\section{REFERENCES}

1. Cameron HA, McKay RD. Adult neurogenesis produces a large pool of new granule cells in the dentate gyrus. J Comp Neurol. 2001;435:406-17.

2. Cameron HA, Woolley CS, McEwen BS, Gould E. Differentiation of newly born neurons and glia in the dentate gyrus of the adult rat. Neuroscience. 1993;56:337-44

3. Altman J, Das GD. Autoradiographic and histological evidence of postnatal hippocampal neurogenesis in rats. J Comp Neurol. 1965;124:319-35.

4. Dupret D, Revest J-M, Koehl M, Ichas F, De Giorgi F, Costet P, Abrous DN, Piazza PV. Spatial relational memory requires hippocampal adult neurogenesis. PLoS ONE. 2008;3:e1959.

5. Snyder JS, Hong NS, McDonald RJ, Wojtowicz JM. A role for adult neurogenesis in spatial long-term memory. Neuroscience. 2005;130:843-52.

6. Swan AA, Clutton JE, Chary PK, Cook SG, Liu GG, Drew MR. Characterization of the role of adult neurogenesis in touch-screen discrimination learning. Hippocampus. 2014;24:1581-91.

7. Denny CA, Burghardt NS, Schachter DM, Hen R, Drew MR. 4- to 6-week-old adultborn hippocampal neurons influence novelty-evoked exploration and contextual fear conditioning. Hippocampus. 2012;22:1188-201.

8. Drew MR, Denny CA, Hen R. Arrest of adult hippocampal neurogenesis in mice impairs single- but not multiple-trial contextual fear conditioning. Behav Neurosci. 2010;124:446-54.

9. Saxe MD, Battaglia F, Wang J-W, Malleret G, David DJ, Monckton JE, Garcia ADR, Sofroniew V, Kandel ER, Santarelli L, Hen R, Drew MR. Ablation of hippocampal neurogenesis impairs contextual fear conditioning and synaptic plasticity in the dentate gyrus. Proc Natl Acad Sci USA. 2006;103:17501-6.

10. Schloesser RJ, Manji HK, Martinowich K. Suppression of adult neurogenesis leads to an increased hypothalamo-pituitary-adrenal axis response. Neuroendocrinology. 2009;20:553-7.

11. Snyder JS, Soumier A, Brewer M, Pickel J, Cameron HA. Adult hippocampal neurogenesis buffers stress responses and depressive behaviour. Nature. 2011;476:458-62.

12. Revest J-M, Dupret D, Koehl M, Funk-Reiter C, Grosjean N, Piazza PV, Abrous DN Adult hippocampal neurogenesis is involved in anxiety-related behaviors. Mol Psychiatry. 2009;14:959-67.

13. Seo D-O, Carillo MA, Chih-Hsiung Lim S, Tanaka KF, Drew MR. Adult hippocampal neurogenesis modulates fear learning through associative and nonassociative mechanisms. J Neurosci. 2015;35:11330-45.

14. David DJ, Samuels BA, Rainer Q, Wang J-W, Marsteller D, Mendez I, Drew M, Craig DA, Guiard BP, Guilloux J-P. Neurogenesis-dependent and -independent effects of fluoxetine in an animal model of anxiety/depression. Neuron. 2009;62:479-93.

15. Santarelli L, Saxe M, Gross C, Surget A, Battaglia F, Dulawa S, Weisstaub N, Lee J, Duman R, Arancio O, Belzung C, Hen R. Requirement of hippocampal neurogenesis for the behavioral effects of antidepressants. Science. 2003;301:805-9.

16. DeCarolis NA, Eisch AJ. Hippocampal neurogenesis as a target for the treatment of mental illness: a critical evaluation. Neuropharmacology. 2010;58:884-93.

17. Drew MR, Hen R. Adult hippocampal neurogenesis as target for the treatment of depression. CNS Neurol Disord Drug Targets. 2007;6:205-18.

18. Fanselow MS, Dong H-W. Are the dorsal and ventral hippocampus functionally distinct structures? Neuron. 2010;65:7-19.

19. Moser MB, Moser El. Functional differentiation in the hippocampus. Hippocampus. 1998;8:608-19.

20. Jung MW, Wiener SI, MCNaughton BL. Comparison of spatial firing characteristics of units in dorsal and ventral hippocampus of the rat. J Neurosci. 1994;14:7347-56.

21. Huff ML, Emmons EB, Narayanan NS, LaLumiere RT. Basolateral amygdala projections to ventral hippocampus modulate the consolidation of footshock, but not contextual, learning in rats. Learn Mem. 2016;23:51-60.

22. Swanson LW, Cowan WM. Hippocampo-hypothalamic connections: origin in subicular cortex, not ammon's horn. Science. 1975;189:303-4.
23. Kjelstrup KG, Tuvnes FA, Steffenach HA, Murison R, Moser EL, Moser MB. Reduced fear expression after lesions of the ventral hippocampus. Proc Natl Acad Sci USA 2002;99:10825-30.

24. McHugh SB, Deacon RMJ, Rawlins JNP, Bannerman DM. Amygdala and ventral hippocampus contribute differentially to mechanisms of fear and anxiety. Behav Neurosci. 2004;118:63-78.

25. Bannerman DM, Yee BK, Good MA, Heupel MJ, Iversen SD, Rawlins JN. Double dissociation of function within the hippocampus: a comparison of dorsal, ventral, and complete hippocampal cytotoxic lesions. Behav Neurosci. 1999; 113:1170-88.

26. Snyder JS, Choe JS, Clifford MA, Jeurling SI, Hurley P, Brown A, Kamhi JF, Cameron HA. Adult-born hippocampal neurons are more numerous, faster maturing, and more involved in behavior in rats than in mice. J Neurosci. 2009;29:14484-95.

27. Snyder JS, Radik R, Wojtowicz JM, Cameron HA. Anatomical gradients of adult neurogenesis and activity: young neurons in the ventral dentate gyrus are activated by water maze training. Hippocampus. 2009;19:360-70.

28. Wu MV, Hen R. Functional dissociation of adult-born neurons along the dorsoventral axis of the dentate gyrus. Hippocampus. 2014;24:751-61.

29. O'Reilly RC, Rudy JW. Conjunctive representations in learning and memory: principles of cortical and hippocampal function. Psychol Rev. 2001;108:311-45.

30. Xu C, Krabbe S, Gründemann J, Botta P, Osakada F, Saur D, Grewe BF, Schnitzer MJ, Callaway EM, Lüthi A. Distinct hippocampal pathways mediate dissociable roles of context in memory retrieval. Cell. 2016;167:961-72.

31. Chang S-D, Chen D-Y, Liang KC. Infusion of lidocaine into the dorsal hippocampus before or after the shock training phase impaired conditioned freezing in a two-phase training task of contextual fear conditioning. Neurobiol Learn Mem. 2008;89:95-105.

32. Maren S, Aharonov G, Fanselow MS. Neurotoxic lesions of the dorsal hippocampus and Pavlovian fear conditioning in rats. Behav Brain Res. 1997;88:261-74.

33. Phillips RG, LeDoux JE. Lesions of the dorsal hippocampal formation interfere with background but not foreground contextual fear conditioning. Learn Mem. 1994;1:34-44.

34. Pentkowski NS, Blanchard DC, Lever C, Litvin Y, Blanchard RJ. Effects of lesions to the dorsal and ventral hippocampus on defensive behaviors in rats. Eur J Neurosci. 2006;23:2185-96.

35. Rudy JW, Matus-Amat P. The ventral hippocampus supports a memory representation of context and contextual fear conditioning: implications for a unitary function of the hippocampus. Behav Neurosci. 2005;119:154-63.

36. Bast $\mathrm{T}$, Zhang $\mathrm{W}-\mathrm{N}$, Feldon J. The ventral hippocampus and fear conditioning in rats. Exp Brain Res. 2001;139:39-52.

37. Gu Y, Arruda-Carvalho M, Wang J, Janoschka SR, Josselyn SA, Frankland PW, Ge S. Optical controlling reveals time-dependent roles for adult-born dentate granule cells. Nat Neurosci. 2012;15:1700-6.

38. Arruda-Carvalho M, Sakaguchi M, Akers KG, Josselyn SA, Frankland PW. Posttraining ablation of adult-generated neurons degrades previously acquired memories. J Neurosci. 2011;31:15113-27.

39. Winocur G, Wojtowicz JM, Sekeres M, Snyder JS, Wang S. Inhibition of neurogenesis interferes with hippocampus-dependent memory function. Hippocampus. 2006;16:296-304.

40. Ge S, Pradhan DA, Ming G-L, Song H. GABA sets the tempo for activity-dependent adult neurogenesis. Trends Neurosci. 2007;30:1-8.

41. Schmidt-Hieber C, Jonas $P$, Bischofberger J. Enhanced synaptic plasticity in newly generated granule cells of the adult hippocampus. Nature. 2004;429:184-7.

42. Lagace DC, Whitman MC, Noonan MA, Ables JL, DeCarolis NA, Arguello AA Donovan MH, Fischer SJ, Farnbauch LA, Beech RD, DiLeone RJ, Greer CA, Mandyam CD, Eisch AJ. Dynamic contribution of nestin-expressing stem cells to adult neurogenesis. J Neurosci. 2007;27:12623-9.

43. Madisen L, Mao T, Koch H, Zhuo J-M, Berenyi A, Fujisawa S, Hsu Y-WA, Garcia AJ, Gu X, Zanella S, Kidney J, Gu H, Mao Y, Hooks BM, Boyden ES, Buzsáki G, Ramirez JM, Jones AR, Svoboda K, Han X, Turner EE, Zeng H. A toolbox of Cre-dependent optogenetic transgenic mice for light-induced activation and silencing. Nat Neurosci. 2012;15:793-802.

44. Sun $M-Y$, Yetman MJ, Lee T-C, Chen Y, Jankowsky JL. Specificity and efficiency of reporter expression in adult neural progenitors vary substantially among nestinCreER $^{\text {T2 }}$ lines. J Comp Neurol. 2014;522:1191-208.

45. Bernier BE, Lacagnina AF, Ayoub A, Shue F, Zemelman BV, Krasne FB, Drew MR Dentate gyrus contributes to retrieval as well as encoding: evidence from context fear conditioning, recall, and extinction. J Neurosci. 2017;37:6359-71.

46. Sparta DR, Stamatakis AM, Phillips JL, Hovelsø N, van Zessen R, Stuber GD. Construction of implantable optical fibers for long-term optogenetic manipulation of neural circuits. Nat Protoc. 2011;7:12-23.

47. Danielson NB, Kaifosh $P$, Zaremba JD, Lovett-Barron M, Tsai J, Denny CA, Balough EM, Goldberg AR, Drew LJ, Hen R, Losonczy A, Kheirbek MA. Distinct contribution of adult-born hippocampal granule cells to context encoding. Neuron. 2016;90:101-12. 
48. Kheirbek MA, Drew $\sqcup$, Burghardt NS, Costantini DO, Tannenholz L, Ahmari SE, Zeng $\mathrm{H}$, Fenton $\mathrm{AA}$, Hen R. Differential control of learning and anxiety along the dorsoventral axis of the dentate gyrus. Neuron. 2013;77:955-68.

49. Kalmbach BE, Chitwood RA, Dembrow NC, Johnston D. Dendritic generation of mGluR-mediated slow after depolarizations in layer 5 neurons of prefrontal cortex. J Neurosci. 2013;33:13518-32.

50. Huckleberry KA, Ferguson LB, Drew MR. Behavioral mechanisms of context fear generalization in mice. Learn Mem. 2016;23:703-9.

51. Byers SL, Wiles MV, Dunn SL, Taft RA. Mouse estrous cycle identification tool and images. PLoS ONE. 2012;7:e35538.

52. Goldman JM, Murr AS, Cooper RL. The rodent estrous cycle: characterization of vaginal cytology and its utility in toxicological studies. Birth Defects Res B Dev Reprod Toxicol. 2007;80:84-97.

53. Watson RE, Wiegand SJ, Clough RW, Hoffman GE. Use of cryoprotectant to maintain long-term peptide immunoreactivity and tissue morphology. Peptides. 1986;7:155-9.

54. Huckleberry KA, Kane GA, Mathis RJ, Cook SG, Clutton JE, Drew MR. Behavioral experience induces zif268 expression in mature granule cells but suppresses its expression in immature granule cells. Front Sys Neurosci. 2015;9:118.

55. Snyder JS, Ferrante SC, Cameron HA. Late maturation of adult-born neurons in the temporal dentate gyrus. PLoS ONE. 2012;7:e48757.

56. Korol DL. Role of estrogen in balancing contributions from multiple memory systems. Neurobiol Learn Mem. 2004;82:309-23.

57. Jasnow AM, Schulkin J, Pfaff DW. Estrogen facilitates fear conditioning and increases corticotropin-releasing hormone mRNA expression in the central amygdala in female mice. Horm Behav. 2006:49:197-205.

58. Phillips RG, Ledoux JE. Differential contribution of amygdala and hippocampus to cued and contextual fear conditioning. Behav Neurosci. 1992;106:274-85.

59. Lassalle JM, Bataille T, Halley H. Reversible inactivation of the hippocampal mossy fiber synapses in mice impairs spatial learning, but neither consolidation nor memory retrieval, in the Morris navigation task. Neurobiol Learn Mem. 2000;73:243-57.

60. Park S, Kramer EE, Mercaldo V, Rashid AJ, Insel N, Frankland PW, Josselyn SA. Neuronal allocation to a hippocampal engram. Neuropsychopharmacology. 2016:41:2987-93.

61. Denny CA, Kheirbek MA, Alba EL, Tanaka KF, Brachman RA, Laughman KB, Tomm NK, Turi GF, Losonczy A, Hen R. Hippocampal memory traces are differentially modulated by experience, time, and adult neurogenesis. Neuron. 2014;83:189-201.

62. Garner AR, Rowland DC, Hwang SY, Baumgaertel K, Roth BL, Kentros C, Mayford M. Generation of a synthetic memory trace. Science. 2012;335:1513-6.

63. Liu X, Ramirez S, Pang PT, Puryear CB, Govindarajan A, Deisseroth K, Tonegawa S. Optogenetic stimulation of a hippocampal engram activates fear memory recall. Nature. 2012;35:221-385

64. Marín-Burgin A, Mongiat LA, Pardi MB, Schinder AF. Unique processing during a period of high excitation/inhibition balance in adult-born neurons. Science. 2012;335:1238-42.

65. Jessberger S, Kempermann G. Adult-born hippocampal neurons mature into activity-dependent responsiveness. Eur J Neurosci. 2003;18:2707-12.

66. Kee N, Teixeira CM, Wang AH, Frankland PW. Preferential incorporation of adultgenerated granule cells into spatial memory networks in the dentate gyrus. Nat Neurosci. 2007;10:355-62.

67. Stone SSD, Teixeira CM, Zaslavsky K, Wheeler AL, Martinez-Canabal A, Wang AH, Sakaguchi M, Lozano AM, Frankland PW. Functional convergence of developmentally and adult-generated granule cells in dentate gyrus circuits supporting hippocampus-dependent memory. Hippocampus. 2010;21: 1348-62.

68. Tashiro A, Makino H, Gage FH. Experience-specific functional modification of the dentate gyrus through adult neurogenesis: a critical period during an immature stage. J Neurosci. 2007;27:3252-9.

69. Ikrar T, Guo N, He K, Besnard A, Levinson S, Hill A, Lee H-K, Hen R, Xu X, Sahay A. Adult neurogenesis modifies excitability of the dentate gyrus. Front Neural Circuits. 2013;7:204
70. Drew LJ, Kheirbek MA, Luna VM, Denny CA, Cloidt MA, Jain S, Scharfman HE, Hen R. Activation of local inhibitory circuits in the dentate gyrus by adult-born neurons. Hippocampus. 2016;26:763-78.

71. Restivo L, Niibori Y, Mercaldo V, Josselyn SA, Frankland PW. Development of adult-generated cell connectivity with excitatory and inhibitory cell populations in the hippocampus. J Neurosci. 2015;35:10600-12.

72. Temprana SG, Mongiat LA, Yang SM, Trinchero MF, Alvarez DD, Kropff E, Giacomini D, Beltramone N, Lanuza GM, Schinder AF. Delayed coupling to feedback inhibition during a critical period for the integration of adult-born granule cells. Neuron. 2015;85:116-30.

73. Kheirbek MA, Klemenhagen KC, Sahay A, Hen R. Neurogenesis and generalization: a new approach to stratify and treat anxiety disorders. Nat Neurosci. 2012;15:1613-20.

74. Sahay A, Wilson DA, Hen R. Pattern separation: a common function for new neurons in hippocampus and olfactory bulb. Neuron. 2011;70:582-8.

75. Nakashiba T, Cushman JD, Pelkey KA, Renaudineau S, Buhl DL, McHugh TJ, Barrera VR, Chittajallu R, Iwamoto KS, McBain CJ, Fanselow MS, Tonegawa S. Young dentate granule cells mediate pattern separation, whereas old granule cells facilitate pattern completion. Cell. 2012;149:188-201.

76. Niibori Y, Yu T-S, Epp JR, Akers KG, Josselyn SA, Frankland PW. Suppression of adult neurogenesis impairs population coding of similar contexts in hippocampal CA3 region. Nat Commun. 2012;3:1253.

77. Sahay A, Scobie KN, Hill AS, O'Carroll CM, Kheirbek MA, Burghardt NS, Fenton AA, Dranovsky A, Hen R. Increasing adult hippocampal neurogenesis is sufficient to improve pattern separation. Nature. 2011;472:466-70.

78. Tronel S, Belnoue L, Grosjean N, Revest J-M, Piazza P-V, Koehl M, Abrous DN. Adult-born neurons are necessary for extended contextual discrimination. Hippocampus. 2012;22:292-8.

79. Hovland $\mathrm{Cl}$. The generalization of conditioned responses: III: Extinction, spontaneous recovery, and disinhibition of conditioned and generalized responses. J Exp Psychol. 1937;21:47-62.

80. Vanz F, Bicca MA, Linartevichi VF, Giachero M, Bertoglio LJ, Moneteiro de Lima TC. Role of dorsal hippocampus $\mathrm{K}$ opioid receptors in contextual aversive memory consolidation in rats. Neuropharmacology. 2018;135:253-67.

81. Winocur G, Frankland PW, Sekeres M, Fogel S, Moscovitch M. Changes in contextspecificity during memory reconsolidation: selective effects of hippocampal lesions. Learn Mem. 2009;16:722-9.

82. Aimone JB, Wiles J, Gage FH. Computational influence of adult neurogenesis on memory encoding. Neuron. 2009;61:187-202.

83. Rangel LM, Alexander AS, Aimone JB, Wiles J, Gage FH, Chiba AA, Quinn LK. Temporally selective contextual encoding in the dentate gyrus of the hippocampus. Nat Commun. 2014;5:3181.

84. Drew MR, Huckleberry KA. Modulation of aversive memory by adult hippocampal neurogenesis. Neurotherapeutics. 2017;14:646-61.

85. Bannerman DM, Deacon RMJ, Offen S, Friswell J, Grubb M, Rawlins JNP. Double dissociation of function within the hippocampus: spatial memory and hyponeophagia. Behav Neurosci. 2002;116:884-901.

86. Amaral DG. Amygdalohippocampal and amygdalocortical projections in the primate brain. Adv Exp Med Biol. 1986;203:3-17.

87. Maren S, Fanselow MS. Synaptic plasticity in the basolateral amygdala induced by hippocampal formation stimulation in vivo. J Neurosci. 1995;15:7548-64.

88. Mello LE, Tan AM, Finch DM. Convergence of projections from the rat hippocampal formation, medial geniculate and basal forebrain onto single amygdaloid neurons: an in vivo extra- and intracellular electrophysiological study. Brain Res. 1992;587:24-40.

89. Henke PG. Hippocampal pathway to the amygdala and stress ulcer development. Brain Res Bull. 1990;25:691-5.

90. Bannerman DM, Grubb M, Deacon RMJ, Yee BK, Feldon J, Rawlins JNP. Ventral hippocampal lesions affect anxiety but not spatial learning. Behav Brain Res. 2003;139:197-213.

91. Adlaf EW, Vaden RJ, Niver AJ, Manuel AF, Onyilo VC, Araujo MT, Dieni CV, Vo HT, King GD, Wadiche Jl, Overstreet-Wadiche L. Adult-born neurons modify excitatory synaptic transmission to existing neurons. eLife. 2017;6:e19886. 